\title{
Subject Entered Into Trial
}

National Cancer Institute

\section{Source}

National Cancer Institute. Subject Entered Into Trial. NCI Thesaurus. Code C161417.

An indication that the subject has met eligibility criteria and is enrolled in the study. The subject may or may not subsequently be randomized. 